\title{
The South African Society of Psychiatrists (SASOP) and SASOP State Employed Special Interest Group (SESIG) Position Statements on Psychiatric Care in the Public Sector
}

\author{
Edited by Bernard Janse van Rensburg \\ SASOP SESIG National Convener \\ Publication sponsored by Dr Reddy's Laboratories
}

\begin{abstract}
Contributors: R Allen (Lentegeur Hospital and SESIG Convener, Western Cape), O Alonso-Betancourt (Department of Psychiatry, Walter Sisulu University (WSU)), J Burns (Department of Psychiatry, University of KwaZulu-Natal (UKZN)), J Chabalala (1 Military Hospital), H Erlacher (Department of Psychiatry, WSU), G Grobler (Department of Psychiatry, University of Pretoria (UP)), Y Jeenah (Division of Psychiatry, University of the Witwatersrand (WITS)), M Kewana (SESIG Convener, Limpopo), L Koen (Department of Psychiatry, Stellenbosch University (SUN)), L Leloka (Division of Psychiatry, WITS), S Mashapu (Department of Psychiatry, UKZN), P Milligan (Department of Psychiatry and Mental Health, University of Cape Town (UCT)), Y Moosa (Division of Psychiatry, WITS), M Motlana (Division of Psychiatry, WITS), R Nassen (Department of Psychiatry, SUN), R Nichol (Department of Psychiatry, University of the Free State (UFS)), D Niehaus (Department of Psychiatry, SUN), J Parker (Department of Psychiatry and Mental Health, UCT), J Pretorius (Department of Psychiatry, UFS), A Rama (Division of Psychiatry, WITS), S Ramlall (Department of Psychiatry, UKZN), J Ras (Department of Psychiatry, SUN), S Rataemane (Department of Psychiatry, University of Limpopo (UL)), S Seedat (Department of Psychiatry, SUN), G Sefala (Department of Psychiatry, UL), D Stein (Department of Psychiatry, SUN), U Subramaney (Division of Psychiatry, WITS), C Szabo (Division of Psychiatry, WITS), I Westmore (SASOP President), S Van Wyk (SESIG Convener, Eastern Cape), S Vermaak (Division of Psychiatry, WITS), Z Zingela (Department of Psychiatry, WSU).
\end{abstract}

\section{Contents}

1. SESIG aims and objectives

2. Background

Position Statement 1 on national mental health policy

3. Proceedings of the SESIG strategic workshop and identified key issues

Position Statement 2 on psychiatry and mental health

3.1 Infrastructure and resources

Position Statement 3 on infrastructure and resources

3.2 Standard treatment guidelines (STGs) and essential drug lists (EDLs)

Position Statement 4 on STGs and EDLS

3.3 Mental health and psychiatric disorders in context of the global burden of disease, including HIV/AIDS and substance-related problems

3.3.1 HIV/AIDS and neuropsychiatry

Position Statement 5(a) on HIV/AIDS in children

Position Statement 5(b) on HIV/AIDS in adults

3.3.2 Substance abuse and addiction

Position Statement 6 on substance abuse and addiction

3.4 Community-centred psychiatry and referral levels Position Statement 7 on community psychiatry and referrals

3.5 Recovery framework

Position Statement 8 on recovery and integration
3.6 Culture, mental health and psychiatry Position Statement 9 on culture, mental health and psychiatry

3.7 Specialty status, medical internship, residency and subspecialty

Position Statement 10 on the specialty status of psychiatry

3.8 Forensic psychiatry

3.8.1 Observandi

Position Statement 11 (a) on forensic observations

3.8.2 State patients

Position Statement 11 (b) on state patients

3.8.3 Mentally ill prisoners

Position Statement 11 (c) on mental ill prisoners

3.9 Security in psychiatric hospitals and units

Position Statement 12 on security in psychiatric hospitals and units

References

Addendum A: 2012 SESIG strategic workshop delegates

Addendum B: Bibliography for workshop sessions

Scope of state sector practice (SESIG workshop session 1)

Policies for state practice (SESIG workshop session 2)

Strategic planning for regions (SESIG workshop session 3)

Teaching and research (SESIG workshop session 4)

Principles for care (SESIG workshop session 5)

SESIG 2012 - 2014 (SESIG workshop session 6) 
Executive summary. National mental health policy: SASOP extends its support for the process of formalising a national mental health policy as well as for the principles and content of the current draft policy. Psychiatry and mental health: psychiatrists should play a central role, along with the other mental health disciplines, in the strategic and operational planning of mental health services at local, provincial and national level. Infrastructure and human resources: it is essential that the state takes up its responsibility to provide adequate structures, systems and funds for the specified services and facilities on national, provincial and facility level, as a matter of urgency. Standard treatment guidelines (STGS) and essential drug lists (EDLS): close collaboration and co-ordination should occur between the processes of establishing SASOP and national treatment guidelines, as well as the related decisions on EDLs for different levels. HIV/AIDS in children: national HIV programmes have to promote awareness of the neurocognitive problems and psychiatric morbidity associated with HIV in children. HIV/AIDS in adults: the need for routine screening of all HIV-positive individuals for mental health and cognitive impairments should also be emphasised as many adult patients have a mental illness, either before or as a consequence of HIV infection, constituting a 'special needs' group. Substance abuse and addiction: the adequate diagnosis and management of related substance abuse and addiction problems should fall within the domain of the health sector and, in particular, that of mental health and psychiatry. Community psychiatry and referral levels: the rendering of ambulatory specialist psychiatric services on a community-centred basis should be regarded as a key strategy to make these services more accessible to users closer to where they live. Recovery and re-integration: a recovery framework such that personal recovery outcomes, among others, become the universal goals by which we measure service provision, should be adopted as soon as possible. Culture, mental health and psychiatry: culture, religion and spirituality should be considered in the current approach to the local practice and training of specialist psychiatry, within the professional and ethical scope of the discipline. Forensic psychiatry: an important and significant field within the scope of state-employed psychiatrists, with 3 recognised groups of patients (persons referred for forensic psychiatric observation, state patients, and mentally ill prisoners), each with specific needs, problems and possible solutions. Security in psychiatric hospitals and units: it is necessary to protect public sector mental healthcare practitioners from assault and injury as a result of performing their clinical duties by, among others, ensuring that adequate security procedures are implemented, appropriate for the level of care required, and that appointed security staff members are appropriately trained and equipped.

S Afr J Psych 2012;18(3):133-148. DOI:10.7196/SAJP.374

\section{SESIG aims and objectives}

The aim of the State Employed Special Interest Group (SESIG) is to promote, maintain and protect the honour and interest of the discipline of psychiatry as a medical specialty with regard to the interests of medical practitioners and psychiatrists primarily in the employ of the state serving psychiatric patients within the public sector, as well as the interests of such patients and the community it serves. The 10 objectives of SESIG are to: (i) foster good relationships among members of the special interest group and the Society; (ii) promote co-operation with other associations involved in mental health; (iii) monitor, evaluate and advise on policies related to the delivery of clinical services and the protection of patients' rights; (iv) promote research appropriate to psychiatry in the public sector; (v) promote appropriate training and evaluation of standards of undergraduate and postgraduate studies; (vi) promote continuing education; (vii) maintain standards by peer review; (viii) protect and uphold the principles of human rights, dignity and ethics of the practice of public sector psychiatry; (ix) oppose unfair discrimination; and $(x)$ promote de-stigmatisation.

\section{Background}

A strategic planning meeting was convened in March 2012 in Windhoek, Namibia, by the South African Society of Psychiatrists (SASOP) Board of Directors (BoD) with the SESIG committee, the different academic heads of department, representative clinical unit heads and other state-employed clinicians, including registrar representatives, from SASOP's different regional subgroup membership. SESIG members from the different regions were consulted regarding the proposed meeting agenda, and representative delegates were selected to attend the meeting according to a proportional quota principle. Delegates who participated in the meeting are listed in Addendum A. Following the meeting, the draft guidelines were made available for comments from the SASOP/SESIG constituency.

The purpose of the meeting was to actively engage with core representative state sector SASOP members on the current most pertinent issues in state psychiatry and develop a short- to mediumterm strategy to effectively address these issues regionally and nationally. The outcome of these sessions informed SASOP's position on different issues, which are communicated formally in this report as specific Position Statements or resolutions. One specific intended outcome of the meeting was to inform SASOP'S participation in the National Mental Health Summit (12 - 13 April 2012). SASOP's representation at the national summit consisted of presenting a message of support by the SASOP president, and plenary and breakaway session presentations (as session chairs and rapporteurs).

It has also been noted that comments have been requested on the draft proposed National Mental Health Policy for South Africa,' which identifies the context for mental healthcare provision, states the vision, mission, values, principles and objectives for services in South Africa (SA), and recognises areas for action, roles and responsibilities. 


\section{Position Statement 1 on national mental health policy}

SASOP has noted the process of formalising national policy for mental healthcare in SA and extends its strong support for the process, as well as the principles incorporated in this policy framework. SASOP strongly encourages the formalisation and implementation of the policy nationally and at provincial level.

\section{Proceedings of the SESIG strategic workshop and identified key issues}

Discussions and presentations during the SESIG meeting in March 2012 in Windhoek covered the following 6 areas (references Addendum B): (i) the scope of state sector practice; (ii) pertaining policies for state practice; (iii) planning per region; (iv) teaching and research; ( $v$ ) accepted principles for care; and (vi) strategic mobilisation in view of set objectives. The perspective of the discussions was that 'while there is no health without mental health, there is also no complete mental health without psychiatry'.

\section{Position Statement 2 on psychiatry and mental health}

As point of departure, it should be acknowledged that psychiatrists should play a central role, along with the other mental health disciplines, in the strategic and operational planning of mental health services at a local, provincial and national level. Specific timeframes, definitions of care at different levels, norms and standards of care, resources to be allocated, and the routine monitoring/ auditing of mental healthcare programs need to be performed in conjunction with psychiatrists on all levels.

The SESIG strategic meeting identified a number of key issues affecting effective service delivery to individuals with mental health problems, including:

- infrastructure for psychiatric infrastructure and human resources

- psychiatric standard treatment guidelines (STGs) and essential drug lists (EDLs)

- mental health and psychiatric disorders in the context of the global disease burden (including HIV and substance-related problems)

- community-centred psychiatric services and referral levels

- recovery frameworks

- culture, mental health and psychiatry

- specialty status, medical internship, residency and sub-specialty.

\subsection{Infrastructure and human resources}

The extensive infrastructural limitations at district and regional levels are currently significant obstacles to the effective and humane assessment and management of patients requiring psychiatric admission or outpatient services. For example, in terms of 72-hour assessment at the point of entry to healthcare services, current legislation was implemented without any budgetary provision on national or provincial level, to allow for, for instance, the transfer of administrative support to local and regional general hospitals (previously performed by the magistrates' offices of the Department of Justice). Furthermore, no provision was made for the adjustment of the physical facilities of these hospitals which have to accommodate the new services (including those for involuntary users). As a consequence, 72-hour assessments are currently predominantly performed in unsafe, inappropriate structures with inadequate trained staff, or a lack thereof, with respect to numbers and expertise.

Previously, budgets for mental health services were integrated in other general health programs. However, it is currently almost impossible to identify and prioritise funds for mental health activities on provincial or facility level. This has worsened the already poor prioritising of mental healthcare in the public health domain over the years. While private facilities are expected to meet stringent and costly criteria when applying for service licenses, no comparable public sector norms and standards have been implemented, e.g., with regard to the capacity of the state's new 72-hour assessment and units in district and regional hospitals. Over the past decade, the state itself has therefore remained largely non-compliant with the requirements of the Mental Health Care Act (MHCA) no. 17 of 2002.

The Infrastructure Unit Support Systems (IUSS) project of the national Department of Health $(\mathrm{DoH})$ and Council for Scientific and Industrial Research (CSIR) refers to levels of the World Health Organization's (WHO's) 'pyramid of care':2,3

- Level V - long-stay facilities, including specialist psychiatric services and forensic services (in psychiatric hospitals)

- Level IV - psychiatric services in general hospitals, including 72-hour assessment facilities and community mental health services (in district and regional hospitals, and at specialist ambulatory community mental healthcare clinics)

- Level III - primary mental healthcare (in primary healthcare clinics)

- Level II - informal community care (e.g. teacher counsellors, religious leaders and traditional healers)

- Level I-self care.

At the same time, the DoH identifies 5 different entities for clinical psychiatric services: assessment and evaluation (outpatients in clinics); 72-hour assessment (inpatient); admission units; psychiatric intensive care; and sub-specialty services (e.g. child and adolescent psychiatric services, geriatrics, co-morbid substance abuse and neuropsychiatry). However, district hospitals render a primary level of care (employing primary care practitioners such as general medical practitioners), while regional hospitals render a specialist level of care (employing specialists such as psychiatrists). In terms of preparation for the National Health Insurance (NHI), it has to be clarified at which level of care a psychiatric admission unit will be and whether a psychiatrist will be employed at this level in a district hospital.

In terms of current budget allocation, hospitals are identified as district (level I/primary care), regional (level II/secondary care) and central (level III/tertiary care) hospitals. Although specialised/ academic/sub-specialty psychiatric services have been rendered in regional and central hospitals for many years, until recently 
psychiatry was, for example, not able to access the National Tertiary Services Grant, as only one maximum security facility in the Eastern Cape was acknowledged as a 'tertiary facility'.

Singular definitions and allocations of the clinical services categories ('72-hour assessment', 'admission unit', 'psychiatric intensive care unit', and 'sub-specialty units') are not adequate; e.g. 72-hour assessments are expected to be conducted in district hospitals (primary care level). Although about 204 district hospital country-wide are currently providing these required (involuntary) services, no facilities were created in which safe and adequate care can be ensured. While this would require a separate area in these district hospitals, with dedicated psychiatric beds, no such facilities exist in most hospitals. Only 10 district hospitals nationally have an admission unit (Freeman, 2011). Currently, the regular 72-hour assessments are often conducted in an inadequate locked room adjacent to casualty sections, or in open-area non-secure medical beds. In terms of the preparation for the NHI, it needs to be clarified whether this categorisation also encompasses specialist care and, if so, whether admission units in district hospitals are required.

Existing national norms and standards for acute units ${ }^{4}$ do not account at all for the academic obligations of several of these units in regional and tertiary hospitals. Academic staff members associated with university health science faculties are jointly appointed by the provincial departments of health and the universities. They are required to provide academic and clinical services rendered on a '30:70' principle, which translates into a 12-hour allocation of the 40-hour week to academic work (teaching and research).

Admission units are supposed to be associated only with specialist regional hospitals. However, many currently identified regional hospitals do not have any structures in which admissions are adequately managed. Several regional hospitals also provide 'intensive care services', where users have to be managed in seclusion during which intensive care nursing is required. Current regional hospitals also provide sub-specialty care to child and adolescent users and geriatric, co-morbid substance and neuropsychiatric services. Some regional hospitals are also rendering a tertiary level of care (employing sub-specialists, or forming part of university academic circuits where undergraduate and postgraduate psychiatry students are trained). Tertiary services are therefore not limited to the few hospitals currently regarded as 'central' hospitals.

The WHO pyramid of service does not account for the categories of users - voluntary, assisted and involuntary - according to the MHCA no. 17 of 2002. Involuntary care often requires special specifications in terms of the facilities in which such users are admitted (e.g. 72-hour assessment units). These categories determine the levels of security, containment and, by deduction, specialisation required to accommodate these different users.
Psychiatric hospitals are regarded as specialist psychiatric facilities, although the MHCA allows for all categories of users (including voluntary and 72-hour assessment services) to be managed in these top-of-the-pyramid facilities. Current long-term facilities in several regions, however, are generally inadequate and often located very far from the patients' families.

The contracted LifeHealth Esidimeni medium-term psychiatric facilities in some provinces, for assisted and involuntary users, have not been adequately accounted for in these classifications.

\section{Position Statement 3 on infrastructure and resources}

As a matter of urgency, it is essential that the state takes up its responsibility, according to Chapter 2 of the MHCA no. 17 of 2002 (among others), to provide adequate structures, systems and funds for the specified services and facilities on national, provincial and facility level, with specific emphasis on district hospital infrastructure capacity. Since the lack of provision of the aforementioned routinely results in poor service conditions, mental health practitioners' clinical judgment, decisions and practice may, in the meantime, be compromised as a result of existing sub-standard infrastructure and poor staffing conditions. It is therefore also necessary from a medico-legal, professional and labour point of view to adequately protect public sector mental healthcare practitioners. Appropriate staffing of facilities and services is required, acknowledging that, in the past, mental health and psychiatric services have been inadequately staffed and many institutions have not been allocated mental health professionals (e.g. tertiary and central hospitals).

\subsection{Psychiatric STG and EDL}

A request for comments on the review of the 2006 STGS and EDLs for adults at hospital-level was issued by the national DoH in October 2010. Although some submissions on the psychiatric STGs and EDLs (Chapter 15) were made by individual psychiatrists and departments of psychiatry, information on the current progress of this process has not been readily forthcoming. It should be noted that, over the past 4 years, SASOP has been in the process of developing STGs for psychiatrists practising in the state and the private sector. It is essential that these guidelines are considered in the national process, to establish integration between STGs and the available essential drugs on the different prescriber and service-rendering levels, from primary and secondary to tertiary and quaternary levels.

It has been reported to the SASOP BoD that, from 2012, all psychiatric drugs will have to be approved nationally by the National Tertiary and Quaternary EDL Committee (NEDLC), and all current provincial drug lists will be withdrawn until a required level of evidence for efficacy of the different existing psychiatric agents has been shown locally. It has been noted, however, that the level of evidence-based proof required for inclusion in the national EDL, as suggested by the NEDLC, does not currently exist for psychiatric 
drugs anywhere worldwide. Since the NEDLC has approved only 1 drug out of 15 submissions made by the Psychiatry Working Group in recent years, it can be foreseen that routine psychiatric practice will be seriously affected. The tertiary/quaternary EDL list will therefore not be aligned with, for example, the proposed SASOP STGs. These imposed limitations will seriously affect the practice of psychiatry in the state and private sectors country-wide.

\section{Position Statement 4 on STG and EDL}

Close collaboration and co-ordination should occur between the processes of establishing SASOP and national STGs, and the related decisions on EDLs for different levels. This will also require liaison with private sector practitioners. It can also be suggested that the authors of the SASOP STGS (who followed a formal peer-review process) and the NEDLC should form a standing committee and/or other structures for ongoing liaison to explore procedural issues, as well as the current and ongoing revision of the current different lists of available drugs. If, however, finalising the national EDL would occur in the absence of such close collaboration and co-ordination in the EDL and STG processes, SASOP will have to express its grave concern, as psychiatry as a specialist clinical discipline will be prejudiced against, while the availability of evidence-based medications will be threatened, in particular, within the public sector.

\subsection{Mental health and psychiatric disorders in the context of the global burden of disease, including HIV and substance-related problems 3.3.1 HIV/AIDS and neuropsychiatry}

HIV remains a significant contributor to the global burden of disease, with most sufferers located in southern Africa. Many acute adult 72-hour observation psychiatric units, medical admission wards and adult psychiatric hospital wards are currently overwhelmed with HIV-related psychiatric presentations, including delirium, dementia, psychosis, mania and depression. A significant proportion of these patients are also diagnosed with tuberculosis (TB) and syphilis.

In this regard, however, a most vulnerable group are women and children, with $40 \%$ of child deaths in SA due to HIV, despite the advent of the SA national rollout of antiretroviral therapy (ART). ART has seen increasing numbers of perinatally HIV-infected children surviving into adolescence and early adulthood. Significant numbers of children, however, present with HIV-associated neurocognitive deficits (HANDs) despite ART initiation, which impact negatively on academic functioning and behaviour.

Furthermore, there are significantly higher rates (up to 50\%) of psychopathology in HIV-positive youths (and adults), involving disorders such as attention deficit hyperactivity disorder (ADHD), depression, anxiety disorders, substance abuse and other risk behaviours. The experience of child and adolescent mental health services (CAHMS) in the Western Cape is that few HIV-positive children access psychiatric care. Considering that large numbers of children in SA are infected or affected by HIV, this means that relatively few are referred for neuropsychiatric assessment. The majority of children referred and who are followed up regularly in CAHMS units, are institutionalised - most with late initiation of ART and some presenting with dementia. Most referrals to child psychiatry services at tertiary level are from tertiary level services such as dedicated HIV clinics and research entities (e.g. KID CRU - the Children's Infectious Disease Clinical Research Unit at Tygerberg Hospital). Very few children are referred from primary settings, seemingly indicating a significant obstacle to care, due to socioeconomic factors, lack of recognition of the problem, or inadequate screening for neuropsychiatric problems.

\section{Position Statement 5(a) on HIV/AIDS in children}

National HIV programmes also have to promote awareness of the neurocognitive problems and psychiatric morbidity associated with HIV in children. It can be suggested that a task team should be established to focus specifically on the needs of long-term survivors of perinatal HIV infection. Specifically, focus is needed on:

- early ART initiation as a prevention strategy

- effective screening to increase the detection of early HIV encephalopathy, subtle neurocognitive deficits and psychopathology

- capacitating at primary level via increased human resources (including increasing sub-specialist input at primary care) and intensified training

- the incorporation of mental health into early intervention programmes

- integrated and comprehensive family-based services at primary level

- strengthening of referral pathways from primary- to tertiary-level CAHMS services

- strengthening HIV prevention and safe-sex psycho-education programmes within existing CAHMS services

- strengthening liaison with the Department of Education to effectively address the educational needs of and support for HIVinfected children.

\section{Position Statement 5(b) on HIV/AIDS in adults}

In addition to increased awareness of HIV in children in national HIV programmes, the need for routine screening of HIV-positive individuals (children, adolescents and adults) for mental health and cognitive impairments should be emphasised. These psychiatric complications of HIV affect critical issues in HIV/AIDS care, such as adherence. Many adult patients have a mental illness, either before or as a consequence of HIV infection. These patients often live under dismal conditions, abuse substances and are poorly compliant with all forms of treatment. They also run the risk of becoming a 'reservoir' for resistant strains of HIV and TB. They represent a 'special needs' group who demand a specific integrated mental-health and infections carepackage under the auspices of specialised primary care teams. 


\subsubsection{Substance abuse and addiction}

Although the management of substance abuse problems does not fall exclusively within the health sector, substance abuse plays a major role in the precipitation and relapse of serious psychiatric conditions, affirming an inextricable link between substance abuse and mental health. Treatment programmes should therefore also fall within the remit of mental health and psychiatric services. Current services fall within packages of care rendered mainly by the Department of Social Development. It is of concern that psychiatric co-morbidity may, therefore, be missed or underestimated, due to a lack of expertise in 'dual diagnosis', assessment and management of substance-related psychiatric disorders in the non-health sectors. Within the different health departments, services and budgets are also severely limited, which negatively affects the capacity to 'rollout' dual diagnosis programmes to all provinces.

\section{Position Statement 6 on substance abuse and addiction}

While the management strategy of substance abuse and addiction involves multisectoral responsibility, including social services, justice and education, the role of health and mental health must be regarded as a core component in a collaborative multisectoral effort. The adequate diagnosis and clinical management of related substance-abuse and addiction problems should, therefore, also fall in the domain of the health sector and, in particular, that of mental health and psychiatry. The necessary resources and infrastructure will have to be made available to render these services effectively.

\subsection{Community-centred psychiatric services and referral levels}

Psychiatry has been the only specialist medical discipline rendering ambulatory specialist services on a community-centred basis for many years. These services include specialised, academic and subspecialty psychiatric services rendered either in the geographical catchment areas of regional or psychiatric hospitals as 'outreach programmes', or as separate 'community psychiatry services' with separate structures and staff based in districts or in provincial departments of (mental) health.

In preparation of $\mathrm{NHI}$ implementation, it is essential that psychiatry is regarded as part of the re-engineering of the primary healthcare (PHC) system in the districts, providing for the appointment of principal psychiatrists on district level to: ensure training of primary care staff; oversee the referral of care users to more specialised levels of care; and ensure appropriate collation of information and conducting of research.

\section{Position Statement 7 on community psychiatry and referrals}

The ongoing rendering of ambulatory specialist psychiatric services on a community-centred basis should be regarded as a key strategy to make these services more accessible to users closer to where they live. In addition, the establishment of community- based day-care centres and residential facilities is regarded as a core component of community-based mental healthcare services, ensuring access to the full range of psychosocial rehabilitation services, including occupational therapy and social services. It is essential that community-centred specialist psychiatric services are established within an appropriate referral system, consisting of: primary mental health and psychiatric (family physician) care; secondary specialist care (in community clinics and regional hospitals); and tertiary and quaternary psychiatric care (in tertiary, central and psychiatric hospitals). In this context, the need for community-based residential, day-care and step-down facilities should also be emphasised.

\subsection{Recovery framework}

The adoption of a recovery framework for psychiatric service users holds the potential for a radical transformation of mental health services in SA. This will occur by empowering consumers through the adoption of a set of values that emphasises the principles of person-centeredness, self-determination and self-management in a positive atmosphere of hope.

\section{Position Statement 8 on recovery and integration}

Essential steps for the adoption of a recovery framework include:

- the promotion of recovery awareness in all aspects of services, such that personal recovery outcomes become the universal goals by which service provision is measured

- the institution of active measures to combat discrimination against individuals with psychosocial disability, within services and on a societal level

- the institution of progressive programs in all services to establish and further develop consumer involvement in service feedback, planning and delivery

- steps to improve accessibility to the wide range of treatment and support services required for recovery

- the strengthening of primary-level and community-based mental health services to improve prevention, rehabilitation and restoration of social roles.

\subsection{Culture, mental health and psychiatry}

Over recent years, the critical role of culture, religion and spirituality in health has become evident in SA. As such, the 'Western scientific' model of healthcare has increasingly been regarded as only one approach that should be adopted next to others, and, in particular, in parallel to traditional African healing practices, with greater emphasis on the unseen, cosmological view of the emotional and relational lives of adherents. The importance of having to reconsider the role of culture, religion and spirituality in health, mental health and psychiatry in SA has, in particular, been emphasised by recent legislation on African traditional health practice. Great emphasis is placed on mental health by the Traditional Health Practitioner's Act no. 35 of 2004, defining it as a significant part of what is regarded as the traditional health practitioner's spectrum of responsibilities. 
A large body of SA and international literature describes the existence of these 2 parallel health systems - the 'formal' and the 'alternative' (or traditional) - while generally advocating a closer collaboration between medical/psychiatric interventions and more traditional or cultural/religious interventions. While confirmation of the formal figures for SA is difficult, from experience it is generally observed that the majority of the population consults a traditional healer or religious practitioner prior to, or concurrently with, a biomedical practitioner. Studies on the pathways to mental healthcare have confirmed this trend.,5 Following the official acknowledgement by WHO in the 1970s of the possible role of traditional healers in primary care, the use of alternative health practices has, in many instances, been encouraged and incorporated by authorities into formal health services as a strategy to address health needs. This has often been the case in under-resourced rural populations with few formal health services at their disposal. ${ }^{7.8}$

In this regard, a review of SA literature was previously undertaken. ${ }^{9}$ A prominent issue raised in the past regarding African traditional health practice has been whether the work by traditional healers should be regarded as religion or psychotherapy. Some writers have compared the traditional healer to the Western psychotherapist, and considered traditional health practice as psychotherapy more so than a religion.10,11 Others referred to African cultural beliefs as being a religious and spiritual practice. ${ }^{12,13}$ The South African Medical Association (SAMA), for example, more recently represented a review of the work of a previous task team on collaboration between traditional healers and medical practitioners that aimed to inform decisionmakers, professionals and non-governmental organisations on the relationship between African traditional healing and Western biomedical systems in SA. ${ }^{14}$ Based on the principle that the patient is pivotal in the healthcare equation and that traditional health practitioners play an important role in Africa, SAMA expressed the view that some degree of co-operation between the 2 systems is desirable. At the same time, it should be noted that many patients with psychiatric conditions are still subject to various forms of abuse through the practices of some traditional healers, e.g. psychotic patents are tied up and beaten, and access to appropriate psychiatric intervention is delayed or restricted.

\section{Position Statement 9 on culture, mental health and psychiatry}

Culture, religion and spirituality should be considered in the current approach to the local practice and training of specialist psychiatrists. This should, however, be performed within the professional and ethical scope of the discipline, and all faith traditions and belief systems in the heterogenous SA society should be respected and regarded equally. In the public sector domain, no preference for one particular tradition should be given over another, as a result of a practitioner or a dominant group being from the one tradition or the other. Building relationships of mutual trust and understanding will require training and health education initiatives aimed at psychiatric practitioners, their patients, carers and students, and cultural and religious practitioners whom patients and their carers may choose to consult. The protection of individuals with psychiatric conditions within traditional and other religious/spiritual healing systems, however, needs to be ensured and all forms of abuse in this context, or neglect and delay with regard to appropriate psychiatric care, should be identified and prevented.

\subsection{Specialty status, medical internship, residency and sub-specialty}

The current bio-psycho-social approach to the practice and training of psychiatry in SA refers to Engel's extended model of healthcare, and forms the basis of the existing multidisciplinary collaboration in mental healthcare between medicine, nursing, psychology, occupational therapy and social work. 15,16

However, the status of psychiatry over the past years has been increasingly undermined by what may be regarded as discrimination and disregard for the role of psychiatry as a unique, independent medical specialty. Psychiatry is often incorrectly regarded and treated by statutory bodies, as well as training and service institutions, as a sub-component of Family Medicine. This disregard is reflected by the fact that psychiatry's academic status as 1 of the 5 major subjects in clinical medicine has been diminished in most faculties of health sciences, that family physicians are appointed by the Heath Professions Council of South Africa (HPCSA) to assess academic departments of psychiatry, and, in terms of line-functions in service structures, that specialist psychiatrists are often expected to report to family physicians. Another example of the compromised status of psychiatry is that the training of medical interns in psychiatry has currently been structured as a 1-month rotation in 'mental health' as part of their Family Medicine block. As far as undergraduate teaching in psychiatry is concerned, there should be an effort to increase teaching and training in mental health and psychiatry on undergraduate level at universities for all health professionals. The sooner awareness is created for mental health issues, the better the outcome in the long run; this should be integrated as a core principle through all the years of training for all professionals who will be in contact with issues surrounding mental health and psychiatric care.

\section{Position Statement 10 on the specialty status of psychiatry}

While the main business of SASOP is to promote, maintain and protect the honour and interest of the discipline of psychiatry as a medical specialty, it is strongly advised that:

- the academic status of psychiatry as 1 of the 5 major clinical disciplines in all schools of clinical medicine in the different SA universities should be restored as a matter of priority

- appropriate management structures for psychiatrists on all levels be created to ensure that the supervision and management of psychiatric services is rendered by psychiatrists themselves

- the training of medical interns in psychiatry should be extended to at least 2 months within departments of psychiatry and not as a sub-programme of Family Medicine 
- appropriate structures and posts be created on the appropriate levels for psychiatric sub-specialists (including child and adolescent, old-age, addiction, consultation-liaison, neuro- and forensic psychiatry).

\subsection{Forensic psychiatry}

Forensic psychiatry constitutes an important and significant field within the scope of state-employed psychiatrists. There are 3 groups of forensic patients, each with their own specific needs, problems and possible solutions: (i) persons referred to designated hospitals for forensic psychiatric observation in terms of the Criminal Procedures Act (CPA) no. 51 of 1977 (referred to as 'observandi'); (ii) state patients admitted to designated hospitals in terms of the MHCA; and (iii) mentally ill prisoners in terms of the MHCA.

\subsubsection{Observandi}

There are currently 10 observation units in the country: Weskoppies and Sterkfontein Hospitals (Gauteng, also serving Mpumalanga and North West); Free State Psychiatric Complex (also serving parts of Northern Cape); Komani (single observations only) and Fort England Hospital (Eastern Cape); Fort Napier Hospital (KwaZulu-Natal); Valkenberg Hospital (Western Cape and parts of Northern Cape); Thabamoopo and Hayani Hospitals (Limpopo); and Bophelong Hospital (single observations only) (North West).

The main problem seems to be the long waiting list for admission to some of the units. Furthermore, there are significant differences between the provinces in the manner in which observations are conducted, which leads to differences between the waiting lists. This was addressed by the national DoH by institution of a task team, consisting of members of the national DoH, Departments of Justice and Constitutional Development, Department of Correctional Services, and South African Police Service. This culminated in a Forensic Mental Health Seminar, held in May 2011. At this occasion, many constructive suggestions were made by all participants; to highlight one, an infrastructure task team assessed each observation site and found that not a single one met the standards, and all had either to be replaced, newly built or, at the very least, significantly altered. Another problem is poor communication between role-players. The task team mentioned above is proof that collaboration between the departments is essential, and can lead to an improvement of services.

\section{Position Statement 11(a) on forensic observations}

At least one observation unit should be established in each province; within provinces, satellite units should be considered to bring the service closer to the people. Observation units should be upgraded according to the standards set by the national DoH. Considering infrastructure, organograms for the adequate staffing of these units should be developed and approved by provincial departments.

\subsubsection{State patients}

Most institutions catering for state patients (usually the same that deal with observations) are well over capacity. The reason for this is that there are only 3 ways of dealing with these patients following improvement: (i) return them to their families (which is often the place where the offences occurred); (ii) secure a place for them in the very limited step-down facilities (halfway houses); or (iii) refer them to institutions for chronic care and rehabilitation, which are too few and mostly not able to provide proper rehabilitation due to poor infrastructure and staffing.

\section{Position Statement 11(b) on state patients}

Rehabilitation must be the emphasis of the care of state patients. The institutions involved in the treatment of such patients should develop a uniform approach towards a rehabilitation programme. State patients on leave need to be cared for within the clinic system, and primary healthcare workers need to be alerted to the special needs of this patient population.

\subsubsection{Mentally ill prisoners}

The problems within this group are two-fold: the administrative process to place a prisoner into a mental health institution is too complicated, according to the MHCA, and there is the issue of safe custody. Generally, the number of mentally ill prisoners requiring treatment at mental health institutions is small and can be handled. In this context, it must also be noted that psychiatric services to the correctional facilities are, at best, very limited, and, at worst, nonexistent. This should be addressed by interdepartmental negotiations.

\section{Position Statement 11(c) on mentally ill prisoners}

Attempts should be made to achieve changes to the MHCA to simplify the procedure of referral. Secure detention of mentally ill prisoners must be assured by adequate infrastructure and staffing. The question of psychiatric services within correctional facilities must be addressed.

\subsection{Security in psychiatric hospitals and units}

The need to rely on certain levels of security, restraint, involuntary confinement and seclusion as part of the challenge to provide appropriate care for acute psychiatric conditions has, historically, been an inherent factor in the creation of space and an environment in which individuals presenting with disturbed, violent or other changed behaviour can be safely and appropriately managed. These behavioural problems may include physical threats to self or others and are often part of the presenting symptoms of a range of conditions, such as acute psychosis, mood or cognitive disorders, as well as substance abuse and personality disorders. This scenario also includes forensic settings, where individuals have been charged with an alleged crime, the seriousness of which often requires specific security measures and procedures to be in place. 
Involuntary admission of users is a standard procedure according to the MHCA, when somebody with a mental illness has lost the capacity to make an informed decision about his/her mental healthcare and is refusing treatment. Regulations according to the MHCA provide clear guidelines for the conditions under which a person may be physically restrained or secluded.

In addition to several designated psychiatric hospitals and psychosocial rehabilitation facilities, many general hospitals, including local district hospitals or regional specialist hospitals, have been designated to perform 72-hour assessments or provide acute care, often to involuntary mental healthcare users. Very few of these facilities have been refurbished to make this additional requirement possible in a sustainable or a safe way, while upholding the stipulated human rights of users as citizens and patients. Acute involuntary care often has to be provided in open medical wards, where users either have to be heavily medicated or physically restrained to their beds. Alternatively, users may be constrained in small confined rooms or areas not suitable for the purpose of safe and supportive custody. General hospitals are also often expected to accommodate the care of voluntary, assisted and involuntary users, for both males and females, in one confined area.

In everyday practice, the restriction of movement of assisted and involuntary users, or their restraint and seclusion, is being done with the assistance of security staff. These workers are either employed as security personnel by the facility itself, or a contract is undertaken by the facility with a security firm to provide general security on the premises. The security staff, as hospital or external employees, often do not have adequate training to deal with medical and psychiatric emergency situations. In fact, these duties are often not formally included in their employment contracts. This may lead to situations of abuse of users' rights, as well as to physical abuse and assault on vulnerable involuntary inpatients. It has also occurred that inadequate or inappropriate security measures and actions, as a result of untrained or unavailable security staff, or due to inadequately designed or equipped facilities, have led to the assault and injury of mental healthcare staff members.

\section{Position Statement 12 on mentally ill prisoners}

An integral part of the realisation of the human rights of mental healthcare users, as protected by current mental health legislation, is to ensure that the physical spaces and structure of facilities for mental healthcare are aligned with the needs and functionality of a spectrum of mental healthcare users, including forensic psychiatric care users. It is also necessary to adequately protect public sector mental healthcare practitioners from assault and injury as a result of performing their clinical duties by, among other, ensuring that adequate security procedures are implemented, appropriate for the level of care that is required, and that appointed security staff members are appropriately trained and adequately equipped.

\footnotetext{
References

1. Department of Health (DoH). National Mental Health Policy for South Africa; Draft 2. Pretoria: DoH, 2010.

2. Freeman M. The Mental Health Act, Infrastructure and Mental Health Clinical Services at Various Level of Care. National Department of Health, Workshop 9 on Norms and Standards. 29 - 30 November 2011

3. IUSS Online. http://www.iussonline.co.za/2011/12/mental-health-workshop-2 (accessed 9 July 2012).

4. Department of Health. Norms Manual for Severe Psychiatric Conditions. Pretoria: DoH, 1998

5. Obiodun OA. Pathways to mental health care in Nigeria. Psychiatr Serv 1995;146(8):823-826.

6. Mkize LP, Uys LR. Pathways to mental health care in Kwazulu-Natal. Curationis 2004;27(3):62-71.

7. Odejide AO, Oyewunmi LK, Ohaeri JO. Psychiatry in Africa: An Overview. Am J Psychiatry 1989;146(6):708-716

8. Okasha A. Focus on Psychiatry in Egypt. Br J Psychiatry 2004;185:266-272.

9. Janse van Rensburg ABR. A changed climate for mental health care delivery in South Africa. Afr J Psychiatry 2009;12(2):157-165.

10. Bührmann MV. Western psychiatry and the Xhosa patient. S Afr Med J 1977;51:464-466.

11. Berg A. Ancestor reference and mental health in South Africa. Transcult Psychiatry 2003;40(2):194-207.

12. Edwards SD, Grobbelaa PW, Makunga NV, et al. Traditional Zulu theories of illness in psychiatric patients. J Soc Psychol 1983;121:213-221.

13. Griffiths JA, Cheetham RWS. Priests before healers - An appraisal of the isangoma or isanusi in Nguni society. S Afr Med J 1982;62:959-960

14. South African Medical Association (SAMA). Bridging the Gap. Potential for a Health Care Partnership between African Traditional Healers and Biomedical Personnel in South Africa. Pretoria: SAMA, 2006.

15. Engel G. The need of a new medical model: a challenge for biomedicine. Science 1997;196:129136.

16. Engel GL. Clinical application of the biopsychosocial model. Am J Psychiatry 1980;137:535-544
} 


\section{Addendum A: 2012 SESIG strategic workshop delegates}

Available places to attend the Windhoek meeting were allocated according to the number of paid-up SASOP state sector members at the time, on a proportional basis from each subgroup.

\begin{tabular}{lll} 
Allocation of places to attend the $\mathbf{2 0 1 2}$ SESIG strategic meeting & \\
\hline & $\begin{array}{l}\text { Proportion of total paid-up SASOP state } \\
\text { sector members (July 2011) } \\
\text { Subgroup }\end{array}$ & Number of delegates \\
\hline Limpopo & $11(8)$ & 3 \\
Northern Gauteng & $39(19)$ & 10 \\
Southern Gauteng & $48(24)$ & 12 \\
KwaZulu-Natal & $17(8)$ & 4 \\
Free State & $17(8)$ & 4 \\
Eastern Cape & $16(8)$ & 4 \\
Western Cape & $54(27)$ & 13 \\
Total & $202(100)$ & 50
\end{tabular}

\section{Participating delegates of the 2012 SESIG strategic workshop (in alphabetical order)}

\begin{tabular}{|c|c|c|c|}
\hline Province & Title & Surname & First name \\
\hline \multirow[t]{4}{*}{ Eastern Cape } & Professor & Alonso-Betancourt & Orlando \\
\hline & $\operatorname{Dr}$ & Erlacher & Helmut \\
\hline & $\mathrm{Dr}$ & van Wyk & Stephanus \\
\hline & $\mathrm{Dr}$ & Zingela & Zukiswa \\
\hline \multirow[t]{4}{*}{ Free State } & $\mathrm{Dr}$ & Katunsi & Emily \\
\hline & Professor & Nichol & Richard \\
\hline & Professor & Pretorius & Paul \\
\hline & $\mathrm{Dr}$ & Westmore & Ian \\
\hline \multirow[t]{3}{*}{ KwaZulu-Natal } & Professor & Burns & Jonathan \\
\hline & $\operatorname{Dr}$ & Mashaphu & Sibongile \\
\hline & Dr & Singh & Keshika \\
\hline \multirow[t]{3}{*}{ Limpopo } & Dr & Chabalala & Jan \\
\hline & Dr & Kewana & Matshele \\
\hline & Dr & Sefala & Gabriel \\
\hline \multirow[t]{7}{*}{ Northern Gauteng } & Dr & Grobler & Gerhard \\
\hline & Dr & Mataboge & Rethabile \\
\hline & Dr & Modisane & Lucas \\
\hline & $\mathrm{Dr}$ & Molete & Maryanne \\
\hline & Dr & Morwamoche & Sekgopetjane \\
\hline & Dr & Nkomo & Nolitha \\
\hline & Professor & Rataemane & Solomon \\
\hline
\end{tabular}

142 SAJP - August 2012 Vol. 18 No. 3 
Participating delegates of the SESIG strategic workshop (in alphabetical order) (continued)

\begin{tabular}{|c|c|c|c|}
\hline Province & Title & Surname & First name \\
\hline \multirow[t]{11}{*}{ Southern Gauteng } & Dr & Janse van Rensburg & Bernard \\
\hline & Professor & Jeenah & Fatima \\
\hline & Dr & Leloka & Liemo \\
\hline & Dr & Moosa & Yusuf \\
\hline & Dr & Motlana & Letumile \\
\hline & Dr & Pillay & Anersha \\
\hline & Dr & Rama & Anusha \\
\hline & Dr & Ramasar & Thriya \\
\hline & Dr & Subramaney & Ugashvaree \\
\hline & Professor & Szabo & Christopher \\
\hline & Dr & Vermaak & Sonja \\
\hline \multirow[t]{10}{*}{ Western Cape } & Dr & Allen & Robin \\
\hline & Dr & Chiliza & Bonginkosi \\
\hline & Professor & Koen & Liezl \\
\hline & Dr & Milligan & Peter \\
\hline & Dr & Nassen & Rene \\
\hline & Professor & Niehaus & Dana \\
\hline & Dr & Parker & John \\
\hline & $\operatorname{Dr}$ & Ras & Johan \\
\hline & Professor & Seedat & Soraya \\
\hline & Professor & Stein & Dan \\
\hline
\end{tabular}

\section{Addendum B: Bibliography for workshop sessions}

With generous sponsorship from Dr Reddy's Laboratories, the first strategic SESIG planning meeting was held in Windhoek, Namibia, from 30 March to 1 April 2012. The workshop was divided into 6 sessions: (i) the scope of state sector practice; (ii) policies for state practice; (iii) strategic planning for regions; (iv) teaching and research; (v) principles for care; and (vi) SESIG 2012 - 2014. During each session, an invited speaker introduced and set out the most pertinent issues, while a panel responded to discussion from the floor. Audio recordings were made of the proceedings and formal minutes were taken. The strategic positions which resulted from the process have been compiled in this document as a series of 12 position statements, to inform the mandates of the SESIG and SASOP executives during its next term (2012 - 2014). Literature which informed the session is listed below.

\section{Scope of state sector practice (SESIG workshop session 1)}

This workshop addressed all 10 SESIG objectives. The proposed issues included: SESIG's purpose and current scope of activities; state sector practice in public health, military, forensic and correctional settings; adult and child/adolescent services; labour relations and professional association; joint appointees for service delivery, and academic activity and relations with 2 employers; training and psychiatric residency; occupation-specific dispensation (OSD); remuneration for work outside of public sector (RWOPS); SESIG structures and membership; and SESIG budget.

\section{Policy}

1. Szabo CP. Psychiatry in South Africa: some reflections. South African Psychiatry Review 2006;9:121-125. 
2. Flisher AJ. Mental health policy in Africa. Afr J Psychiatry 2010;13:81-83.

3. Janse van Rensburg ABR. A framework for current public mental health care practice in South Africa. Afr J Psychiatry 2007;10(4):205-209.

4. Lazarus R. Managing de-institutionalisation in a context of change: The case of Gauteng, South Africa. South African Psychiatry Review 2005;8:65-69.

5. Thom R. Mental health service policy, implementation and research in South Africa - are we making progress? South African Journal of Psychiatry 2004;10(2):32-37.

\section{Culture, mental health}

Van Niekerk J. Traditional leaders formalised? S Afr Med J 2012;102(3):105-106.

2. Mbatha N, Street RA, Ngcobo M, Gqelani N. Sick certificates by South African traditional health practitioners: Current legislation, challenges and the way forward. S Afr Med J 2012;102(3):129132

3. Asmal L, Mall S, Kritzinger J, Chiliza B, Emsley R, Swartz L. Family therapy for schizophrenia cultural challenges and implementation barriers in the South African context. Afr J Psychiatry 2011:14:367-371

4. Grobler C, Weiss EA, Lebelo E, Malerotho E. Culture, religion and psychosis - a case study from Limpopo Province, South Africa. Afr J Psychiatry 2011;14:239-240.

5. Sorsdahl KR, Flisher AJ, Wilson Z, Stein DJ. Explanatory models of mental disorders and treatment practices among traditional healers in Mpumulanga, South Africa Afr J Psychiatry 2010;13:284-290

6. Janse van Rensburg ABR. A changed climate for mental health care delivery in South Africa. Afr IJ Psychiatry 2009;12(2):157-165.

7. Burns JK, Jhazbhay K, Emsley RA. Causal attributions, pathway to care and first-episode psychosis: a South African perspective. Int I Soc Psychiatry 2011;57(5):538-545.

\section{Policies for state practice (SESIG workshop session 2)}

This workshop addressed the third SESIG objective: to monitor evaluate and advise on policies related to the delivery of clinical services and the protection of patients' rights. Proposed issues included: a policy framework for the delivery of state clinical services for adult and child and adolescent users, e.g. the MHCA and proposed NHI system; referral systems (between different levels of care and between public and private sectors); definition of levels services; norms and standards; funding for mental health and psychiatric care, including the National Tertiary Services Grant (NTSG); STGs; primary secondary, tertiary and quaternary EDLs; and generic medication.

\section{EDLs}

. Eaton J. Ensuring access to psychotropic medication in sub-Saharan Africa Afr J Psychiatry 2008; 11:179-181.

2. Parrish AG. Impact of tertiary and quaternary service funding processes on medication selection in the SA essential drugs programme. Afr J Psychiatry 2008;11:93-95.

3. Szabo CP. Evidence, resources and an open formulary for the state sector. South African Psychiatry Review 2006;:193-195.

4. Emsley R, Booysen F. Cost-effectiveness of an atypical conventional antipsychotic in South Africa. South African Journal of Psychiatry 2004:10(3):58-66.

\section{MHCA, mental health review boards}

. Bateman C. A mental health review board in action. S Afr Med J 2012:102(2):72.

2. Bateman C. Dismal use of legal safety net for mental health patients. S Afr Med 2012;102(2):72.

3. Janse van Rensburg ABR. Tracking the legal status of a cohort of inpatients on discharge from 72-hour assessment unit. Afr J Psychiatry 2011;14:318-320.

4. Janse van Rensburg B. Applications to Mental Health Review Boards by institutions in Gauteng South African Journal of Psychiatry 2011;17(2):62.

5. Moosa MYH, Jeenah FY. A review of the applications for involuntary admissions made to the Mental Health Review Boards by institutions in Gauteng in 2008. South African Journal of Psychiatry 2010;16(4):125-130.

6. Jonsson G, Moosa MYH, Jeenah FY. The Mental Health Care Act: Stakeholder compliance with Section 40 of the Act. South African Journal of Psychiatry 2009;15(2):37-42.

7. Moosa MYH, Jeenah FY. Involuntary treatment of psychiatric patients in South Africa. Afr J Psychiatry 2008;11:109-112.
8. Szabo CP. The Mental Health Care Act: challenges and opportunities. South African Psychiatry Review 2006;9:1-5.

9. Segal J. Thom R. Consent procedures and electroconvulsive therapy in South Africa: impact of the Mental Health Care Act. South African Psychiatry Review 2006;9:206-215.

10. Zabow T. Institutional management of the mentally ill in South Africa. South African Journal of Psychiatry 2005;11(3):76.

11. Freeman M. New mental health legislation in South Africa - principles and practicalities: A view from the Department of Health. South African Psychiatry Review 2002:5:4-8

12. Burns JK. Implementation of the Mental Health Care Act (2002) at district hospitals in South Africa: Translating principles into practice. S Afr Med J 2008;98(1):46-51.

\section{Funding}

Genth Afr J Psychiatry 2011;14(3):173-175

2. Janse van Rensburg ABR, JassatW. Acute mental health care according to recent mental health legislation. Part II. Activity-based costing. Afr J Psychiatry 2011;14(2):23-29.

3. Burns JK. Mental health services funding and development in KwaZulu-Natal: A tale of inequity and neglect. S Afr Med J 2010;100(10):662-666

\section{Norms and standards}

. Janse van Rensburg A, Janse van Rensburg ABR. Acute mental health care according to recent mental health legislation. Part III. Structuring space for acute in-patient care. Afr J Psychiatry 2011;14(3):112-119.

2. Joska JA, Flisher AJ. Needs and services at an in-patient psychotherapy unit. Afr J Psychiatry 2007;10:149-156.

3. Muller L, Flisher AJ. Standards for the mental health care of people with severe psychiatric disorders in South Africa: Part 1. Conceptual issues. South African Psychiatry Review 2005;8:140-145

4. Muller L, Flisher AJ. Standards for the mental health care of people with severe psychiatric disorders in South Africa: Part 2. Methodology and results. South African Psychiatry Review 2005;8:146-152

\section{Services, referral, community}

Makanjula V Abdulmalik J.Public and community health psychiatry in Africa: from humble beginnings to a promising future. Afr J Psychiatry 2011;14:89-91.

2. Botha U. Community rehabilitation for schizophrenia patients. South African Journal of Psychiatr 2011;17(1):32.

3. Alonso-Betancourt O, Morales-Herrera M. Community rehabilitation for schizophrenia patients: Is it feasible in South Africa? South African Journal of Psychiatry 2010;16(3):66-68

4. Szabo CP. Should state sector community psychiatry be hospital based? A local, and personal, perspective. Afr J Psychiatry 2010;13:1

5. Botha U, Koen L, Oosthuizen P, Joska J, Hering L. Assertive community treatment in the South African context. Afr J Psychiatry 2008;11:272-275.

6. Moosa MYH, Jeenah FY. Community psychiatry: An audit of the services in southern Gauteng South African Journal of Psychiatry 2008;14(2):36-43.

7. Janse van Rensburg B. Community placement and reintegration of service users from longterm mental health care facilities. South African Psychiatry Review 2005:8:100-103.

\section{Strategic planning for regions (SESIG workshop session 3)}

This workshop addressed all 10 SESIG objectives. Proposed issues included: different regional perspectives, structures and capacity; regional states of affairs, including the population in the area, available psychiatrists, management structures, services, facilities and funding; information systems and data collection; regional planning cycles; psychiatrists' role in planning and management of services; and prioritisation of mental health and psychiatric care.

\section{Epidemiology, services review}

Wright GEB, Niehaus DJH, Koen L, Drögemöller BI, Warnich L. Psychiatric genetics in South Africa: cutting a rough diamond. Afr J Psychiatry 2011;14:355-366.

2. Temmingh $\mathrm{H}$, Stein DJ, Seedat S, Williams DR. The prevalence and correlates of hallucination in a general population sample: findings from the South African Stress and Health Study. Afr Psychiatry 2011;14:211-217.

3. Khasakhala L, Sorsdah KR, Harder VS, Williams DR, Stein DJ, Ndetei DM. Lifetime menta disorders and suicidal behaviour in South Africa. Afr J Psychiatry 2011:14:134-139. 
4. Makanjuola V, Abdulmalik J. Public and community health psychiatry in Africa: from humble beginnings to a promising future. Afr J Psychiatry 2011;14:89-91.

5. Moodley SV, Matjila MJ, Moosa MYH. Epidemiology of substance use among secondary schoo learners in Atteridgeville, Gauteng. South African Journal of Psychiatry 2012;18(1):2-9.

6. Ramlagan S, Peltzer K, Matseke G. Epidemiology of drug abuse treatment in South Africa. South African Journal of Psychiatry 2010;16(2):40-49

7. Peltzer K, Ramlagan S. Illicit drug use in South Africa: Findings from a 2008 national populationbased survey. South African Journal of Psychiatry 2010;16(1):8-15.

8. Myers B, Van Heerden MS, Grimsrud A, Myer L, Williams DR, Stein DJ. Prevalence and correlates of atypical patterns of drug use progression: findings from the South African Stress and Health Study. Afr J Psychiatry 2011;14:38-44

9. Peltzer K, Davids A, Njuho P. Alcohol use and problem drinking in South Africa: findings from a national population-based survey. Afr J Psychiatry 2011;14:30-37.

10. Kleinties S, Lund C, Flisher AJ. A situational analysis of child and adolescent mental health services in Ghana, Uganda, South Africa and Zambia. Afr J Psychiatry 2010;13:132-139.

11. Burns J. Dispelling a myth: Developing world poverty, inequality, violence and socia fragmentation are not good for outcome in schizophrenia. Afr J Psychiatry 2009;12:200-205.

12. Peltzer K, Ramlagan S, Cannabis use trends in South Africa. South African Journal of Psychiatry 2007;13(4):126-131.

13. Kleintjes S, Flisher AJ, Fick M, et al. The prevalence of mental disorders among children adolescents and adults in the Western Cape, South Africa. South African Psychiatry Review 2006; 9:157-160.

14. Matjila MJ. The importance of epidemiological studies of psychiatric conditions. Comment: Thom R. South African Journal of Psychiatry 2006;12(4):86-90

15. Singh D, Mkize DL. Psychiatric epidemiology - an introduction. South African Journal of Psychiatry 2006;12(4):91-93.

16. Singh D, Mkize DL. Psychiatric epidemiology - a historical perspective. South African Journa of Psychiatry 2006;12(4):94-96.

17. Singh D. Selected challenges in psychiatric epidemiology South African Journal of Psychiatry 2006;12(4):97-99

\section{Eastern Cape}

agents used in para-suicide in Buffalo City. South African Journal of Psychiatry 2009:15(3):63-66.

2. Parrish AG. Impact of tertiary and quaternary service funding processes on medication selection in the SA essential drugs programme. Afr J Psychiatry 2008;1 1:93-95.

3. Meel BL. Suicide in the Transkei region of South Africa. South African Psychiatry Review 2006:9:61-62.

\section{Free State}

1. Strydom N, Pienaar C, Dreyer A et al. Profile of forensic psychiatric inpatients referred to the Free State Psychiatric Complex, 2004 - 2008. South African Journal of Psychiatry 2011;17(2):40-43.

2. Struwig W, Pretorius PJ. Quality of psychiatric referrals to secondary-level care. South African Journal of Psychiatry 2009:15(2):33-36.

3. Smit P, Pretorius PJ. University of the Free State medical students' view of at-risk drinking behaviour and psychoactive substance use. South African Journal of Psychiatry 2009;15(1):13-18

4. Calitz FJW, Janse van Rensburg PHJ, de Jager PP, et al. Psychiatric evaluation of intellectually disabled offenders referred to the Free State Psychiatric Complex, 1993 - 2003. South African Journal of Psychiatry 2007:13(4):147-152

5. Calitz FJW, Veitch M, Verkhovsky A, Nieuwoudt D, Myburg J, Joubert G. The general profile of children and adolescents with major depression referred to the Free State Psychiatric Complex South African Journal of Psychiatry 2007;13(4):132-136.

6. Barrett SP, Du Plooy J, Du Toit J, Wilmans S, Calitz FJW, Joubert G. Profile of mentally ill offenders referred to the Free State Psychiatric Complex. South African Journal of Psychiatry 2007:13(2):5658.

7. Du Toit EH, Kruger JM, Swiegers SM, et al. The profile analysis of attempted-suicide patients referred to Pelonomi Hospital for psychological evaluation and treatment from 1 May 2005 to 30 April 2006. South African Journal of Psychiatry 2008;14(1):20-25.

8. Calitz FJW, Janse van Rensburg PHJ, Fourie C, Liebenberg E, Van den Berg C, Joubert G. Psychiatric evaluation of offenders referred to the Free State Psychiatric Complex according to sections 77 and/or 78 of the Criminal Procedures Act. South African Journal of Psychiatry 2006;12(3):47-50.

9. Meyer SJ, Slabber M, Janse van Rensburg PHJ, Nel M. Use of the Judicial Section 9 Certification in the Free State. South African Journal of Psychiatry 2004;10(4):104-108.

10. Mosotho L, Louw D, Calitz FJW. Schizophrenia among Sesotho speakers in South Africa. Afr Psychiatry. 2011;14:50-55.

11. Mosotho NL, Louw DA, Calitz FJW, Esterhuyse KGF. Depression among Sesotho speakers in Mangaung, South Africa. Afr J Psychiatry 2008;11:35-43.

\section{KwaZulu-Natal}

. Paruk, S, Ramlall S, Burns JK. Adolescent-onset psychosis: A 2-year retrospective study of adolescents admitted to a general psychiatric unit. South African Journal of Psychiatry 2009;15(4):86-92

2. Saloojee S. Routine pre-admission screening for a medical illness in aggressive patients who required sedation in the emergency department - necessary or not? South African Journal of Psychiatry 2009;15(3):67-71.

3. Burns JK. Xenophobia - evolved 'outgroup' hatred or product of a toxic social environment? South African Journal of Psychiatry 2008;14(4):120-121.

4. Mkize DL. Human rights abuses at a psychiatric hospital in KwaZulu-Natal. South African Journal of Psychiatry 2007;13(4):137-142

5. Mashaphu S, Mkize DL. HIV sero-positivity in patients with first-episode psychosis. South African Journal of Psychiatry 2007;13(3);90-94

6. Nakin DCT, Joubert G, Pretorius PJ, Van Vuuren MJV. Evaluation of attempted-suicide management in a rural district of KwaZulu-Natal. South African Journal of Psychiatry 2007;13(2):52-55.

7. Mkize DL, Green-Thompson RW, Ramdass P, Mhlaluka G, Dlamini N, Walker J. Mental health services in KwaZulu-Natal. South African Journal of Psychiatry 2004;10(1):8-13.

8. Naidoo S, Mkize DL. Prevalence of mental disorders in a prison population in Durban, South Africa. Afr J Psychiatry 2012;15:30-35.

9. Burns JK, Jhazbhay K, Emsley R. Cannabis use predicts shorter duration of untreated psychosis and lower levels of negative symptoms in first-episode psychosis: a South African study. Afr Psychiatry 2010;13:395-399.

10. Burns JK. A Southern Alliance for Research and Innovation in Mental Health Afr J Psychiatry 2009;12:181-185.

11. Naidu T, Ramlall S. Establishing psychiatric registrars' competence in psychotherapy: a portfolio based model. Afr J Psychiatry 2008:11:264-27

12. Ngcobo M, Pillay BJ. Depression in African women presenting for psychological services at a general hospital. Afr J Psychiatry 2008;11:133-137.

13. Mkize DL. Post traumatic stress disorder symptoms in a psychiatric population not presenting with trauma: a preliminary study. Afr J Psychiatry 2008;11:51-53.

14. Lasich AJ, Paruk N, Ramparsad J. A survey of the prevalence of diabetes type 2 amongst schizophrenics in a chronic care treatment facility. Afr J Psychiatry 2007;10:143-146.

15. Ramlall S, Chipps J, Mars M. Impact of the South African Mental Health Care Act No. 17 of 2002 on regional and district hospitals designated for mental health care in KwaZulu-Natal. S Afr Med J 2010;100(10):667-670

16. Burns JK. Mental health services funding and development in KwaZulu-Natal: A tale of inequity and neglect. S Afr Med J 2010;100(10):662-666.

17. Burns JK. Mental health advocacy - lessons from HIV activism. S Afr Med J 2010;100(10):654-655.

18. Burns JK, Esterhuizen T. Poverty, inequality and the treated incidence of first-episode psychosis - an ecological study from South Africa. Soc Psychiatry Psychiatr Epidemiol 2008;43(4):331-335.

\section{Limpopo}

1. Grobler C, Weiss EA, Lebelo E, Malerotho E. Culture, religion and psychosis - a case study from Limpopo Province, South Africa. Afr J Psychiatry 2011;14:239-240.

2. Bach JM, Louw D. Depression and exposure to violence among Venda and Northern Sotho adolescents in South Africa. Afr J Psychiatry 2010;13:25-35.

\section{Northern Gauteng}

1. Fine G, Alison HC, Van der Westhuizen D, Krüger C Predicting frequency of suicide attempts of adolescent outpatients at Weskoppies Hospital using clinical and demographic characteristics. South African Journal of Psychiatry 2012;18(1):22-26.

2. Kotze C, De Wet PH. A 4-year review of psychiatrists' participation in prosecutorial workshops on criminal capacity. South African Journal of Psychiatry 2011:17(4):112-117.

3. Kotzè AME, Van Delft WF, Roos JL. Continuity of care of outpatients with schizophrenia in Pretoria. South African Journal of Psychiatry 2010;16(3):80-83

4. Lippi G, Smit DJ, Jordaan JC, Roos JL. Suicide risk in schizophrenia - a follow-up study after 20 years, Part 1: Outcome and associated social factors. South African Journal of Psychiatry 2009:15(3):56-62.

5. Lippi G, Smit DJ, Jordaan JC, Roos JL. Suicide risk in schizophrenia - a follow-up study after 20 years, Part 2: Symptomatology and pharmacotherapy. South African Journal of Psychiatry 2009;15(4):79-85

6. Kotzé C, King MP, Joubert PM. What do patients with psychotic and mood disorders know about their illness and medication? South African Journal of Psychiatry 2008;14(3):84-90

7. Henning MP, Krüger C, Fletcher L. HIV sero-positivity in recently admitted and long-term psychiatric in-patients: prevalence and diagnostic profile. Afr J Psychiatry 2012;15:47-53.

8. Krüger C, Lewis C. Patient and social work factors related to successful placement of long-term psychiatric in-patients from a specialist psychiatric hospital in South Africa. Afr J Psychiatry 2011;14:120-129

9. Krüger C, Rosema D. Risk factors for violence among long-term psychiatric in-patients: a comparison between violent and non-violent patients. Afr J Psychiatry 2010;13:366-375.

10. Khamker N, Moola NM, Roos JL, Rheeder P. Profile of mortality of patients admitted to Weskoppies Psychiatric Hospital in South Africa over a 5-year period (2001 - 2005). Afr Psychiatry 2010;13:211-217.

11. Maydell RJ, Van der Walt C, Roos IL, Scribante L, Ladikos A. Clinical characteristics and premorbid variables in childhood onset schizophrenia: a descriptive study of twelve cases from a schizophrenia founder population. Afr J Psychiatry 2009;12:144-148.

12. Mahomedy Z, Van der Westhuizen D, Van der Linde MJ, Coetsee J. Persistence of attention 
diagnosed with attention deficit/hyperactivity disorder. South African Psychiatry Review 2007:10:93-98

13. Van Staden CW, Joubert PM, Pickworth GE, et al. The conceptualisation of 'soft skills' among medical students before and after curriculum reform. South African Psychiatry Review 2006;9:33-37.

\section{Southern Gauteng}

1. Jansevan Rensburg B. Applications to Mental Health Review Boards by institutions in Gauteng South African Journal of Psychiatry 2011;17(2):62

2. Moosa MYH, Jeenah FY. A review of the applications for involuntary admissions made to the Mental Health Review Boards by institutions in Gauteng in 2008. South African Journal of Psychiatry 2010;16(4):125-130.

3. Moosa MYH, Jeenah FY. The use of restraints in psychiatric patients. South African Journal of Psychiatry 2009;15(3):72-75.

4. Jonsson G, Moosa, MYH, Jeenah FY. The Mental Health Care Act: Stakeholder compliance with Section 40 of the Act. South African Journal of Psychiatry 2009:15(2):37-42.

5. Van Deventer C, Couper I, Wright A, Tumbo J, Kyeyune C. Evaluation of primary menta health care in North West province - a qualitative view. South African Journal of Psychiatry 2008;14(4):136-140.

6. Kazadi NJB, Moosa MYH, Jeenah FY. Factors associated with relapse in schizophrenia. South African Journal of Psychiatry 2008;14(2):52-62

7. Moosa MYH, Jeenah FY. Community psychiatry: An audit of the services in southern Gauteng. South African Journal of Psychiatry 2008;14(2):36-43.

8. Moosa MYH, Jeenah FY. Treating depression in HIV/AIDS. South African Journal of Psychiatry 2007;13(3):86-88.

9. Moosa MYH, Jeenah FY, Kazadi NJB. Treatment adherence. South African Journal of Psychiatry 2007;13(2):40-45

10. Moosa MYH, Jeenah FY. CT scans in psychiatric patients - an exploratory study at Chris Han Baragwanath Hospital. South African Journal of Psychiatry 2007;13(1):22-25

11. Moosa MYH, Jeenah FY, Mouton C. ECG changes in patients on chronic psychotropic medication. South African Journal of Psychiatry 2006:12(3):42-46.

12. Moosa MYH, Benjamin R, Jeenah FY. A review of multispousal relationships - psychosocia effects and therapy. South African Journal of Psychiatry 2006;12(2):12-14

13. Lucas L, Stevenson D. Institutional victimisation in post-apartheid South Africa. South African Journal of Psychiatry 2005:11(3):90-99.

14. Moosa MYH, Jeenah FY, Vorster M. Repeat non-fatal suicidal behaviour at Johannesburg Hospital. South African Journal of Psychiatry 2005;11(3):84-88.

15. Janse van Rensburg ABR. Tracking the legal status of a cohort of inpatients on discharge from a 72-hour assessment unit. Afr J Psychiatry 2011:14:318-320.

16. Janse van Rensburg ABR. Available resources and human rights - a South African perspective Afr J Psychiatry 2011;14(3):173-175

17. Janse van Rensburg A, Janse van Rensburg ABR. Acute mental health care according to recent mental health legislation. Part III. Structuring space for acute in-patient care. Afr J Psychiatry 2011:14(3):112-119.

18. Janse van Rensburg ABR, Jassat W. Acute mental health care according to recent mental health legislation. Part II. Activity-based costing. Afr J Psychiatry. March 2011;14(2):23-29.

19. Janse van Rensburg ABR. Acute mental health care and South African mental health legislation. Part I - Morbidity, treatment and outcome. Afr J Psychiatry 2010;13(5):382-389.

20. Janse Van Rensburg ABR, Olorunju S. Diagnosis and treatment of schizophrenia in a genera hospital based acute psychiatric ward Afr J Psychiatry 2010;13:204-221.

21. Säll L, Salamon E, Allgulander C, Owe-Larsson B. Psychiatric symptoms and disorders in HIV infected mine workers in South Africa A retrospective descriptive study of acute first admissions. Afr J Psychiatry 2009;12:206-212.

22. Janse van Rensburg ABR. Clinical profile of acutely ill psychiatric patients admitted to a genera hospital psychiatric unit. Afr J Psychiatry 2007:10(3):159-163.

23. Moosa MYH, Jeenah FY. The assessment of undergraduate psychiatry training: a paradigm shift. South African Psychiatry Review 2007;10:88-91

24. Janse van Rensburg B, Bracken C. Acute psychiatric in-patients tested for HIV status: a clinica profile. South African Psychiatry Review 2007;10:83-85

25. Janse van Rensburg ABR. Long-term care of children and adolescents with intellectua disability and severe physical abnormalities. Journal of Child and Adolescent Mental Health 2007;19(2):115-121.

26. Segal J, Thom R. Consent procedures and electroconvulsive therapy in South Africa: impact of the Mental Health Care Act. South African Psychiatry Review 2006;9:206-215

27. Subramaney U. Traumatic stress and psychopathology: experiences of a trauma clinic. South African Psychiatry Review 2006;9:105-107.

28. Moosa $Y$, Jeenah $Y$, Pillay $P$, Vorster M, Liebenberg R. Non-fatal suicidal behaviour at the Johannesburg General Hospital. South African Psychiatry Review 2005;8:104-110.

29. Janse van Rensburg B. Community placement and reintegration of service users from longterm mental health care facilities. South African Psychiatry Review 2005;8:100-103.

30. Lazarus R. Managing de-institutionalisation in a context of change: The case of Gauteng, South Africa. South African Psychiatry Review 2005:8:65-69.

31. Myers $B$, Parry CDH. Access to substance abuse treatment services for black South Africans: indings from audits of specialist treatment facilities in Cape Town and Gauteng. South African Psychiatry Review 2005;8:15-19.

32. Subramaney U. Certification rates: a closed unit's experience. South African Psychiatry Review 2004; $7: 31-32$

33. Moosa MYH, Jeenah FY. An analysis of acute admissions to a general hospital psychiatric unit South African Psychiatry Review 2002;5:16-18.

\section{Western Cape}

1. Ras J. Koen L. Botha UA Niehaus DJH. An audit of non-urgent general adult referrals to Stikland State Psychiatric Facility. South African Journal of Psychiatry 2011:17(4):104-107.

2. Botha U. Community rehabilitation for schizophrenia patients. South African Journal of Psychiatry 2011;17(1):32

3. Koen L, Jonathan R, Niehaus DJH. Cannabis use and abuse correlates in a homogeneous South African schizophrenia population. South African Journal of Psychiatry 2009;15(1):8-12.

4. Joska JA, Stein DJ, Flisher AJ. HIV/AIDS and psychiatry: Towards the establishment of a pilo programme for detection and treatment of common mental disorders in people living with HIV/AIDS in Cape Town. South African Journal of Psychiatry 2008;14(4):123-124.

5. Wilson DAB, Flisher AJ, Welman M. Psychiatric emergency service users at Groote Schuur Hospital, Cape Town. South African Journal of Psychiatry 2005;1 1(3):80-83.

6. Lachman A, Cloete KJ, Kidd M, Schoeman R. The clinical utility and cost effectiveness of routine thyroid screening in adult psychiatric patients presenting at Stikland Hospital, Cape Town, South Africa. Afr J Psychiatry 2012;15:36-4

7. Parry CDH, Plüddemann A, Myers B, Wechsberg WM, Flisher AJ. Methamphetamine use and sexual risk behaviour in Cape Town, South Africa: A review of data from 8 studies conducted between 2004 and 2007. Afr J Psychiatry 2011;14:372-376.

8. Myers B, Louw J, Pasche S. Gender differences in barriers to alcohol and other drug treatment in Cape Town, South Africa. Afr J Psychiatry 2011;14:146-153.

9. Govender RC, Oosthuizen P, Cloete KJ. Diagnostic outcome of patients referred to psychiatry with medically unexplained symptoms: a retrospective study. Afr J Psychiatry 2011;14:45-49.

10. Vos PJ, Cloete KJ, Le Roux A, Kidd M, Jordaan GP. A retrospective review of trends and clinical characteristics of methamphetamine-related acute psychiatric admissions in a South African context. Afr J Psychiatry 2010;13:390-394

11. Weich L, Pienaar W. Occurrence of comorbid substance use disorders among acute psychiatric inpatients at Stikland Hospital in the Western Cape, South Africa. Afr J Psychiatry 2009;12:213-

12. Myers B, Fakier N, Louw J. Stigma, treatment beliefs, and substance abuse treatment use in historically disadvantaged communities Afr J Psychiatry 2009;12:218-222.

13. Koen L, Magni P, Niehaus DJH, Le Roux A. Antipsychotic prescription patterns in Xhosa patients with schizophrenia or schizoaffective disorder. Afr J Psychiatry 2008:11:287-290.

14. Botha U, Koen L, Oosthuizen P, Joska J, Hering L. Assertive community treatment in the South African context. Afr J Psychiatry 2008;11:272-275

15. Van Zyl M, Oosthuizen PP, Seedat S. Post traumatic stress disorder: undiagnosed cases in a tertiary inpatient setting. Afr J Psychiatry 2008:11:119-122.

16. Ganasen KA, Parker S, Hugo CJ, Stein DJ, Emsley RA, Seedat S. Mental health literacy: focus on developing countries. Afr J Psychiatry 2008;11:23-28.

17. Joska JA, Flisher AJ. Needs and services at an in-patient psychotherapy unit. Afr J Psychiatry 2007:10:149-156.

18. Kleintjes S, Flisher AJ, Fick M, et al. The prevalence of mental disorders among children adolescents and adults in the western Cape, South Africa. South African Psychiatry Review 2006;9:157-160

19. Ward $C L$, Mertens JR, Flisher AJ, et al. Substance abuse and HIV risk behaviours amongst primary health care service users in Cape Town. South African Psychiatry Review 2005;8:160165.

20. Crede A, Geduld H, Wallis L. Assessment of routine laboratory screening of adult psychiatric patients presenting to an emergency centre in Cape Town. S Afr Med J 2011;101 (12):891-894.

\section{Teaching and research (SESIG workshop session 4)}

This session addressed SESIG objectives 4 - 7: to promote research appropriate to psychiatry in the public sector; to promote appropriate training and evaluation of standards of undergraduate and postgraduate studies; to promote continuing education; and to maintain standards by peer review. The proposed issues included: psychiatry's status as an academic discipline; the training of psychiatrists in SA (faculties of health sciences, and the SA College of Psychiatry); training of general practitioners and medical internship; continuing professional development (CPD); SESIG and SASOP's role in promoting teaching standards and research in the state sector; 
the structuring of service rendering and academic responsibility of joint appointees within faculties of health sciences and provincial health departments; psychiatric residency: recruitment, curriculum development, requirements and assessment; residents' issues, such as workload, access to and availability of teachers/supervisors, and mentoring; and development and retaining of academic psychiatric staff members.

\section{Training}

1. NaiduT, Ramlall S. Establishing psychiatric registrars' competence in psychotherapy: a portfolio Naidu T, Ramlall S. Establishing psychiatric registra
based model. Afr J Psychiatry 2008;11:264-271

2. Moosa MYH, Jeenah FY. The assessment of undergraduate psychiatry training: a paradigm shift. South African Psychiatry Review 2007;10:88-91.

3. Van Staden CW, Joubert PM, Pickworth GE, et al. The conceptualisation of 'soft skills' among medical students before and after curriculum reform. South African Psychiatry Review 2006;:33-37.

4. Szabo CP. Academia and service delivery, a polemic. South African Psychiatry Review 2003;6:1.

\section{Sub-specialisation publications}

1. Kaliski S. Will forensic psychiatry survive DSM-5? Afr J Psychiatry 2012;15:13-15.

2. Ogunlesi $A O$, Ogunwale A, De Wet $P$, Roos L, Kaliski S. Forensic psychiatry in Africa: prospects and challenges. Afr J Psychiatry 2012;15:3-7.

3. Van Heerden S, Uwakwe R, Potochnick F. The future of old age psychiatry in Africa. Afr J Psychiatry 2011;14:343-345.

4. Vythilingum B, Chiliza B. Consultation liaison psychiatry in Africa - essential service or unaffordable luxury? Afr J Psychiatry 2011;14:257.

5. Beaumont C, Friedlander W, Ndetei D. Addiction psychiatry. Afr J Psychiatry 2011;14:169-171.

6. Molteno C, Adams C, Njenga F. Sub-specialties in psychiatry in Africa - intellectual disability Afr J Psychiatry 2011;14:1-3.

7. Robertson B, Omigbodun O, Gaddour N. Child and adolescent psychiatry in Africa: luxury or necessity? Afr J Psychiatry 2010;13:329-331. Stein DJ, Szabo CP, Driss Moussaoui D, Gureje O. Psychiatric sub-specialization in Africa - introduction to a series. Afr J Psychiatry 2010;13:157 159

\section{Research}

1. Stein DJ, Szabo P. Psychiatry research in South Africa: reason for cautious celebration? Afr J Psychiatry 2011;14:86.

2. Burns JK. A Southern Alliance for Research and Innovation in Mental Health. Afr J Psychiatry 2009;12:181-185.

3. Burns JK, Szabo CP, Herrman H. Building editorial capacity in low- and middle-income countries: the case of the African Journal of Psychiatry. European Science Editing 2011;37(1):35.

\section{Principles for care (SESIG workshop session 5)}

This workshop addressed SESIG objectives 7 - 10: to maintain standards by peer review; to protect and uphold the principles of human rights, dignity and ethics of the practice of (public sector) psychiatry; to oppose unfair discrimination; and to promote de-stigmatisation. Proposed issues included: principles that should govern state sector psychiatric care; standards of care; the protection of human and patient rights; professional and ethical practice; peer review; discrimination against the profession and persons living with a psychiatric condition; anti-stigma and advocacy in general; and educational and support programs for sufferers and relatives.

\section{Stigma}

1. Van Heerden MS, Hering L, Dean C, Stein DJ. Providing psychiatric services in general medica settings in South Africa: Mental health-friendly services in mental health-friendly hospitals. South African Journal of Psychiatry 2008;14(1):2-6.

\section{Human rights}

Rangaka T. South African Human Rights Commission Public Enquiry. Afr J Psychiatry 2007;10:233-239.

2. Mkize DL. Human rights abuses at a psychiatric hospital in KwaZulu-Natal. South African Journal of Psychiatry 2007;13(4):137-142

3. Burns JK. The mental health gap in South Africa: a human rights issue. The Equal Rights Review 2011;6:99-114.

4. Burns JK. Mental health and inequity: a human rights approach to inequality, discrimination and mental disability. Health Hum Rights 2010;11(2):19-31.

\section{Advocacy/education}

1. Burns JK. Mental health advocacy - lessons from HIV activism. S Afr Med J 2010;100(10):654 655.

2. Pooe JM, Sokudela B, Roos JL, Motlana LM, Dlamini N, Snyman M. Testing the effectiveness of existing psycho-educational material (The Alliance Programme) for patients suffering from schizophrenia in the South African context. Afr J Psychiatry 2010;13:302-308.

3. Myers B, Fakier N, Louw J. Stigma, treatment beliefs, and substance abuse treatment use in historically disadvantaged communities Afr J Psychiatry 2009;12:218-222.

4. Ganasen KA, Parker S, Hugo CJ, Stein DJ, Emsley RA, Seedat S. Mental health literacy: focus on developing countries. Afr J Psychiatry 2008;11:23-28

5. Kakuma R, Kleintjes S, Lund C, Drew N, Green A, Flisher AJ. Mental health stigma: What is being done to raise awareness and reduce stigma in South Africa? Afr J Psychiatry 2010;13:1 16-124.

\section{SESIG 2012- 2014 \\ (SESIG workshop session 6)}

The last workshop again addressed all 10 objectives and proposed issues, including: SESIG and SASOP's mobilisation and strategic positioning in the medium term for 2012 - 2014; a mandate from the constituency for state sector practice in public health, military, forensic and correctional settings; action plans and time frames; accountability of SESIG representatives; SESIG/SASOP relationships, co-operation, alliances and advocacy (e.g. SASOP special interest groups/task teams/divisions: forensic, child and adolescent, private; DoH/SAMA/SAPPF/other; advocacy groups); and a business plan and structures to achieve obligations. 
148 SAJP - August 2012 Vol. 18 No. 3 